\title{
Erratum: Two-proton radioactivity within a generalized liquid drop model [Phys. Rev. C 101, 014301 (2020)]
}

J. P. Cui (崔建坡), Y. H. Gao (高永浩), Y. Z. Wang (王艳召), and J. Z. Gu (顾建中)

(Received 10 August 2021; published 31 August 2021)

DOI: 10.1103/PhysRevC.104.029902

The experimental $2 p$ radioactivity half-lives of ${ }^{6} \mathrm{Be},{ }^{12} \mathrm{O}$, and ${ }^{16} \mathrm{Ne}$ were misprinted so that the corresponding $\log _{10} H F$ values of the last column are not correct and misprints have also been discovered for the $\log _{10} H F$ values of ${ }^{19} \mathrm{Mg}$ and ${ }^{45} \mathrm{Fe}$ in our paper. The corrected data are listed in Table I. Nevertheless, the conclusions of our paper are not affected.

We thank Professor X. Li for pointing out the misprints in our paper.

TABLE I. The experimental and calculated $2 p$ radioactivity half-lives of the ground-state to ground-state transitions. The $Q_{2 p}^{\text {expt. }}$ and $\log _{10} T_{1 / 2}$ values are measured in $\mathrm{MeV}$ and seconds, respectively.

\begin{tabular}{llccrr}
\hline \hline Nuclei & $Q_{2 p}^{\text {expt. }}(\mathrm{MeV})$ & $\log _{10} T_{1 / 2}^{\text {expt. }}(\mathrm{s})$ & $\log _{10} T_{1 / 2}^{\mathrm{GLDM}}(\mathrm{s})$ & $\log _{10} T_{1 / 2}^{\mathrm{ELDM}}(\mathrm{s})$ & $\log _{10} T_{1 / 2}^{\text {for. }}(\mathrm{s})$ \\
\hline${ }_{4}^{6} \mathrm{Be}$ & $1.371(5)$ & $-20.30_{-0.03}^{+0.03}$ & $-19.37_{-0.01}^{+0.01}$ & -19.97 & -21.95 \\
${ }_{8}^{12} \mathrm{O}$ & $1.638(24)$ & $>-20.20$ & $-19.17_{-0.08}^{+0.13}$ & -18.27 & -18.47 \\
& $1.820(120)$ & $-20.94_{-0.21}^{+0.43}$ & $-19.46_{-0.07}^{+0.13}$ & & -0.93 \\
& $1.790(40)$ & $-21.10_{-0.13}^{+0.18}$ & $-19.43_{-0.03}^{+0.04}$ & & -1.48 \\
& $1.800(400)$ & $-21.12_{-0.26}^{+0.78}$ & $-19.44_{-0.20}^{+0.30}$ & & -1.67 \\
${ }_{10}^{16} \mathrm{Ne}$ & $1.330(80)$ & $-20.64_{-0.18}^{+0.30}$ & $-16.45_{-0.21}^{+0.23}$ & -16.60 & -1.68 \\
& $1.400(20)$ & $-20.38_{-0.13}^{+0.20}$ & $-16.63_{-0.05}^{+0.05}$ & -11.72 & -15.94 \\
${ }_{12}^{19} \mathrm{Mg}$ & $0.750(50)$ & $-11.40_{-0.20}^{+0.14}$ & $-11.79_{-0.42}^{+0.47}$ & & -16.16 \\
${ }_{26}^{45} \mathrm{Fe}$ & $1.140(50)$ & $-2.07_{-0.21}^{+0.24}$ & $-2.71_{-0.57}^{+0.61}$ & -10.66 & -3.75 \\
& $1.154(16)$ & $-2.55_{-0.12}^{+0.13}$ & $-2.87_{-0.18}^{+0.19}$ & -2.43 & -1.66 \\
\hline \hline
\end{tabular}

